\title{
Pontes e Viadutos e a Cidade Contemporânea: Pontes ou zonas Fronteiriças na Cidade?
}

\author{
Puentes y Viaductos y la Ciudad Contemporánea: Puentes o Zonas \\ Fronterizas en la Ciudad? \\ Bridges and Viaducts and the Contemporary City: Bridges or Border \\ Areas in the City?
}

Fabiane Krolow ${ }^{1}$

José Serafim Bertoloto ${ }^{2}$

\begin{abstract}
Resumo
Diferenças e concepções de fronteiras, em zonas fronteiriças urbanas. A interconexão entre terrestre e águas, a problemática entre fronteiras, espaços semelhantes, diferentes e miscigeno. As ligações possíveis em Cuiabá Mato Grosso através da Ponte Júlio Muller. O presente artigo propõe uma análise em relação aos diferentes processos de reterritorialização e ressignificação nos espaços criados na cidade com a construção de Pontes e Viadutos, buscando entender a efetiva criação de "pontes" culturais na cidade. A análise realizada no artigo tem como objeto de estudo da principal Ponte de Cuiabá, na região metropolitana do Vale do Rio Cuiabá, que une as cidades de Cuiabá e Várzea Grande.
\end{abstract}

Palavras-Chave: Cidade Contemporânea; Cultura Contemporânea; Obras de Arte da Engenharia; Pontes e Viadutos.

\section{Resumen}

Diferencias y concepciones de fronteras, en zonas fronterizas urbanas. La interconexión entre tierra y aguas, la problemática entre fronteras, espacios semejantes, diferentes y miscigeno. Las conexiones posibles en Cuiabá Mato Grosso a través de Puente del Puente Júlio Muller. El presente artículo propone un análisis en relación a los diferentes procesos de reterritorialización y resignificación en los espacios creados en la ciudad con la construcción de Puentes y Viaductos, buscando entender la efectiva creación de "puentes" culturales en la ciudad. El análisis realizado en el artículo tiene como objeto de estudio del principal Puente de Cuiabá, en la región metropolitana del Valle del Río Cuiabá, que une las ciudades de Cuiabá y Várzea Grande.

Palabras claves: Ciudad Contemporánea; Cultura Contemporánea; Obras de Arte de la Ingeniería; Puentes y Viaductos.

Abstract

\footnotetext{
1 (Mestranda no Programa de Pós-Graduação em Estudos de Cultura Contemporânea/UFMT; Professora no Departamento de Arquitetura e Urbanismo da Universidade de Cuiabá; Cuiabá, Mato Grosso, Brasil; fabianekrolow@gmail.com)

${ }^{2}$ (Doutor em Comunicação e Semiótica, PUC/SP; Professor Colaborador do Programa de Pós-Graduação em Estudos de Cultura Contemporânea/IL/UFMT; Docente no Departamento de Arquitetura e Urbanismo e do Programa de Pós-Graduação em Ensino da Universidade de Cuiabá; Cuiabá, Mato Grosso; Brasil; serafim.bertoloto@gmail.com).
} 
Differences and conceptions of frontiers in urban border areas. The interconnection between land and water, the problem of borders, similar spaces, and different miscigeno. Possible connections in Cuiabá, Mato Grosso through the Júlio Müller bridge. This article proposes an analysis on the different process of reterritorialization and reframing the spaces created in the city with the construction of Bridges and Viaducts, seeking to understand the effective creation of cultural "bridges" in the city. The analysis in this article is the main Cuiabá bridge in Cuiabá river valley, which links the cities of Cuiabá and Várzea Grande.

Key-words: Contemporary City; Contemporary Culture; Engineering Works of Art; Bridges and Viaducts.

\section{Introdução}

Vemos as cidades como aglomerados urbanos, com ou sem planejamento, no entanto com adaptações do cotidiano das práticas e espaços. As cidades se formam com tessitura da multiculturalidade que as constroem, onde vemos as relações entre espaço e tempo, que transformam espaços pelo paradigma da tecnologia de informação e formas de processos sociais que ocorrem pelo processo constante de transformação histórica, tendo um perfil real de transformação profundamente diverso, e podemos perceber a evolução das formas urbanas em vários contextos (CASTELLS, 1999).

A construção e evolução das cidades se dão com a conexão de espaços através do sistema viário proposto em cada cidade, o qual parte de um plano diretor de direcionamento de como a cidade deve crescer estabelecendo zonas de usos e ocupação urbana, delimitações territoriais urbanas para cada espaço da cidade e assim também definindo classificações para as vias que promovem o fluxo nas cidades, onde a topografia e geografia do local impõem vales, e em muitos casos com cursos d'água, se faz necessária a proposta de pontes, e com o crescimento da cidade, os congestionamentos trazem a inserção de viadutos, e trincheiras, mostrando a importância dessas obras na cidade com a ideia de possibilidade de conexões entre lugares. São pontos de referência que ao passo em que promovem união de espaços, são limitadores geográficos em suas vias ou cursos d'água.

A delimitação de cidades se dá por linhas de fronteiras estabelecidas por fatores sociais, culturais, étnicos, econômicos e políticos, o que em geral se dá por meio de rios, tipos de fronteiras naturais como marcos físicos Silva e Tourinho (2017), os quais além de serem referencia de linhas de fronteiras são barreiras topográficas, necessitando de pontes para ligações urbanas.

Ao olhar para esses espaços conhecidos como obras de arte da engenharia vemos que seu principal objetivo hoje, é propiciar o fluxo em geral de veículos como conexão de espaços, no entanto criam também, novos espaços urbanos. $\mathrm{O}$ trabalho apresenta o olhar para a Ponte Júlio Muller, por permitir de formas diversas ou não, "pontes" culturais, tendo o rio como elo na poética contemporânea dessa região metropolitana. 
Esse artigo tem como objetivo apresentar formas diversas de processos de reterritorização e ressignificação nos espaços criados entre cidades ou na cidade com a construção de obras de Pontes e Viadutos, na região metropolitana do Vale do Rio Cuiabá, nas cidades de Cuiabá e Várzea Grande, que propõem ou não a possibilidade e "pontes" culturais na cidade contemporânea.

A discussão do artigo trás um olhar para os espaços urbanos que são delimitados com a inserção de pontes e viadutos no espaço urbano, tendo como objeto de estudo a Ponte Júlio Müller situada entre duas maiores cidades de Mato Grosso, Cuiabá e Várzea Grande, traz também a observação dos traços históricos culturais presentes nessa obra, sendo um espaço urbano de ligação das cidades sobre o rio, o que é parte da cidade contemporânea, da região metropolitana do vale do rio Cuiabá. Além de identificar nesse lugar, traços que apresentam ressignificações e reterritorialização e traços culturais presentes, sendo em práticas de espaço ou em representações artísticas em face à uma reflexão sobre as "Pontes" culturais propostas com Pontes e Viadutos entre as cidades de Cuiabá e Várzea Grande.

O presente trabalho é parte do projeto de pesquisa de Mestrado em Estudos de Cultura Contemporânea, o qual tem como objetivo o estudo e análise da estética/poética das pontes e viadutos na região metropolitana do Vale do Rio Cuiabá na contemporaneidade, com as principais obras de arte de engenharia dentro do perímetro urbano das cidades envolvidas, Cuiabá e Várzea Grande, sendo portanto, um resumo de resultados da pesquisa, realizada por meio de análise teórica, mapeamento, levantamento em uma cartografia desses espaços na cidade e por meio de observações através de estudos de cunho etnográficos.

\section{Processo histórico e o desenvolvimento urbano de Cuiabá/Várzea Grande}

O espaço da Ponte Júlio Muller entre as cidades de Cuiabá e Várzea Grande, em Mato Grosso e suas transformações em relação às alterações e processos históricos do desenvolvimento urbano do local. Entre as cidades de Cuiabá e Várzea Grande, na região do porto de Cuiabá, no ano de 1942 surgiu um novo espaço criado sobre o rio, a Ponte Júlio Muller, depois da Ponte de Ferro sobre o rio Coxipó, a primeira ponte em concreto armado, trazendo possibilidades de novas conexões entre os dois espaços que antes se comunicavam apenas por via fluvial, viabilizando o acesso direto, trouxe de imediato inovações e novas possibilidades comerciais, sociais e culturais, sua forma se transformou ao longo do tempo, afim de continuar atendendo à essas possibilidades, mudando a largura da sua caixa viária e também sua forma no contexto geral, em função da logística do comércio local, hoje com novas propostas com finalidades para atender ao fluxo viário e a cultura local, dada a sua 
importância para a cultura das cidades. A figura 1 apresenta a ponte em sua última transformação, obra finalizada em 2014 com a vista superior do Rio Cuiabá e da cidade de Cuiabá.

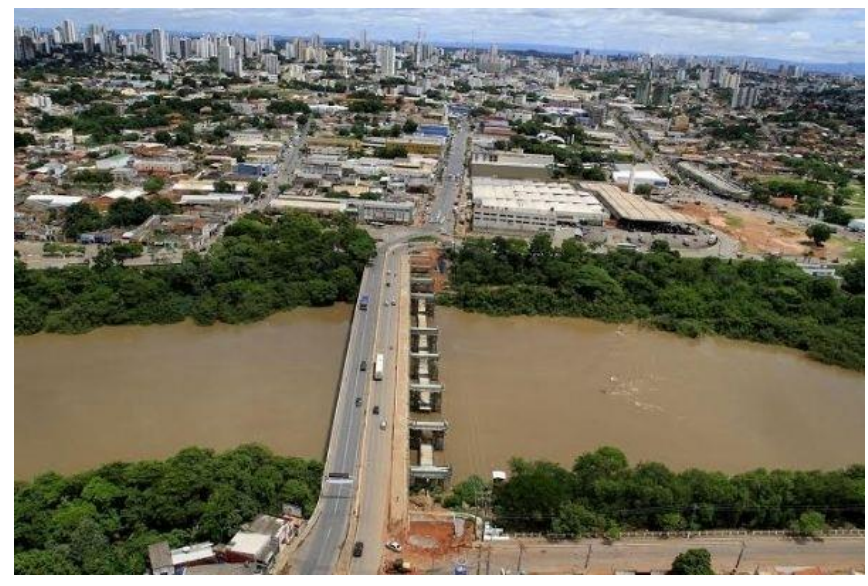

Figura 1 - A ponte em sua última transformação Fonte: Rogério Florentino/Olhar direto, 2018

A ponte Júlio Muller foi inaugurada em 20 de janeiro de 1942 (Figura 2), pelo então governador Júlio Strubing Müller, ao ser entregue às cidades, a obra trouxe mudanças sócias e políticas para a cidade que estava "emperrada em todos os sentidos" confirma afirma Wilson Pires de Andrade (2016), em sua matéria publicada em 20 de janeiro de 2016 no site de notícias "olhar direto"".

Em sua primeira forma

A ponte tinha então 224 metros de extensão com 6 metros de largura de pista para dois veículos de passeio, além de 40 metros de vão para navegação, com arcos decorativos alinhados junto ao parapeito do passeio com vigas que atravessavam a ponte de um lado ao outro do arco. A ponte foi construída no estilo Art Decó, com a aplicação das artes, a visibilidade na obra do desenho industrial, o uso de novos materiais, e as formas aerodinâmicas acentuadas, retilíneas, simétricas e ziguezagueantes. (WILSON PIRES DE ANDRADE, 2018).

Uma das principais funções de qualquer ponte é propor a comunicação entre dois lugares separados por alguma barreira, algum tipo de fronteira em especial para possibilitar o transito de veículos, no entanto suas funções para as cidades vão muito além. A primeira ponte em concreto armado construída sobre o rio Cuiabá, como afirma o jornalista Wilson Pires de Andrade (2018) em suas matérias, teve grande importância na permanência da capital em Cuiabá devido à logística e consequentemente no desenvolvimento do estado, a obra “Garantiu a comunicação entre o norte e a capital.", além de trazer benefícios para a infraestrutura urbana local, como o fato de que "Depois de três anos de concreto Várzea 
Grande recebeu energia elétricas." Essa primeira ponte existe ainda hoje em 2018, no entanto passou por algumas transformações que alteraram a sua forma, e emerge novas transformações na cidade contemporânea.

O adensamento populacional através da intensificação do processo de urbanização da região em meados de 1980, trouxe a necessidade da duplicação da ponte, foi construído então pelo governo de Várzea Grande a nova via, sentido Várzea-Grande - Cuiabá, inaugurada em 15 de março de 1985. Essa forma da ponte está presente na paisagem cuiabana ainda hoje sendo um dos principais acessos, e um importante cartão-postal da cidade e região como é possível ver na Figura 03, que inclusive é um cartão-postal da cidade.

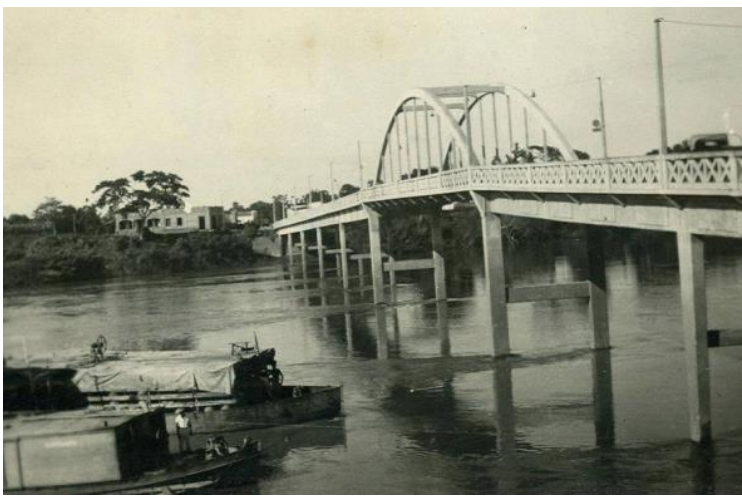

Figura 2 - A primeira Ponte Júlio Müller

Fonte: Almanaque Cuiabá, 2016.

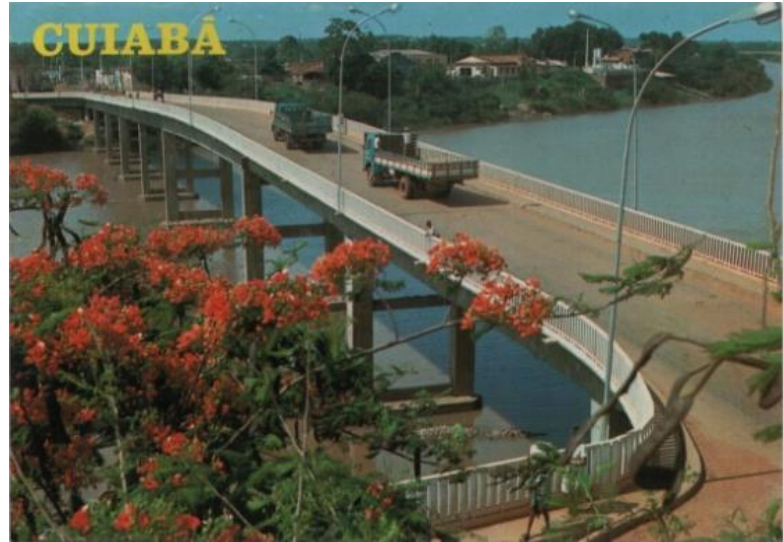

Figura 3 - Cartão postal da Ponte após a sua primeira alteração.

Fonte: Leilões BR, 2017.

Com as intervenções realizadas para o megaevento que ocorreu em várias cidades do Brasil, a Copa do Mundo de 2014, várias obras foram ou seriam construídas também na cidade de Cuiabá, entre elas a obra de adequação viária para implantação do sistema de transporte V. L. T. (Veículo Leve Sobre trilhos) onde era necessário realizar adequação da estrutura da Ponte Júlio Muller, então sua forma foi novamente alterada. "Foi construída uma pista lateral na Ponte Júlio Muller para as obras de adequações do sistema viário realizadas na região metropolitana para a Copa de 2014. A ponte possuí extensão de 350 metros e foi ampliada do lado direito da Ponte, no sentido Várzea-Grande-Cuiabá, obra realizada entre 2013 e 2014.” (GAZETA DIGITAL, 2014)

Na obra de ampliação, conforme mostra a reportagem de Wilson Pires de Andrade (2018)0, sua forma permaneceu a mesma, no entanto a largura total da caixa viária foi alterada, aumentando a laje do tabuleiro da ponte, onde deveria passar o veículo do V.L.T. que ainda hoje não foi instalado, e não tem previsão para ser instalado, no entanto a obra da 
ampliação existe e criou um corredor para pedestres sobrepondo de forma usual as calçadas estreitas existentes na ponte.

Mesmo com o intenso fluxo de veículos entre as duas cidades, e a ponte Júlio Muller sendo uma das principais pontes para atender as necessidades desse transito, ao lado da Ponte em Cuiabá existe uma praça, e nas proximidades está o cais do Porto com uma parte já revitalizada para a cidade e outra parte do cais com obras em prospecção, isso sem pensar nos moradores da região e nos próprios pescadores, é importante considerar que na forma atual da Ponte, a calçada existente não permite o caminhar das pessoas com segurança conforme a figura 04.

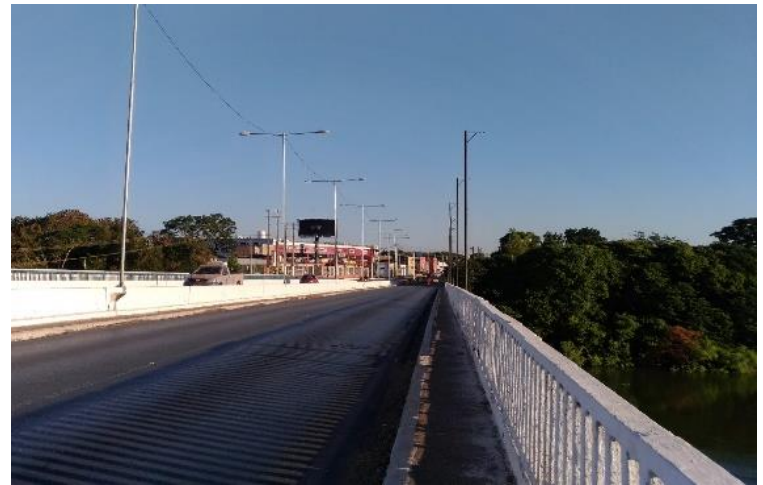

Figura 04 - Calçada da Ponte Júlio Müller Fonte: Autora, 2017.

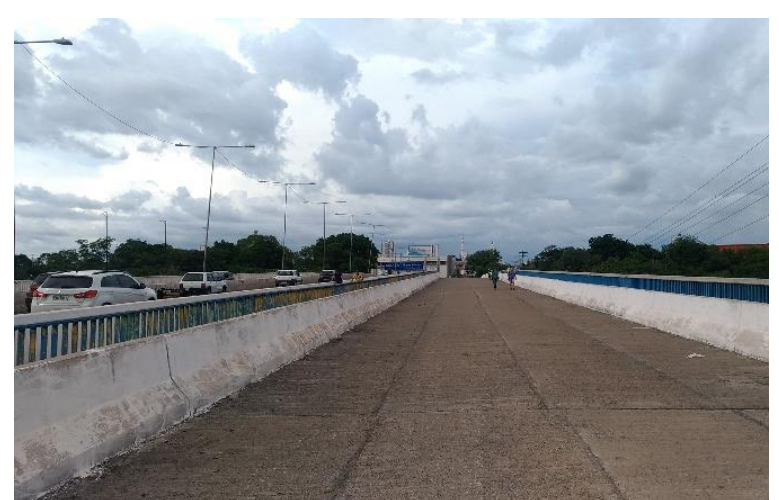

Figura 05 - Ampliação construída para o V.L.T. Fonte: Autora, 2018.

A ampliação da ponte realizada para a implantação do V.L.T. trouxe um espaço maior na outra lateral da ponte, já que o mesmo não foi implantado, no entanto percebesse que o desenho não foi pensado para o caminhar e o convívio das pessoas no local, mesmo este sendo um local com privilegio como afirma Cullen (2013) ao falar sobre o fato de as pontes estarem posicionadas sobre um curso d'água, em geral em uma cota mais alta que seu entorno, geralmente proporciona a vista da paisagem urbana, a partir da ponte, o que Cullen (2013, p. 26) chama de privilégio, afirmando que "Verifica-se, igualmente, que há linhas privilegiadas susceptíveis de ocupação: a linha ao longo da guarda de um ponte, por exemplo, parece constituir um local de eleição, pela qualidade imediata da vista que proporciona sobre a paisagem" (CULLEN, 2013, p. 26), o que temos em qualquer ponte, um ponto na cidade com uma vista privilegiada, como a figura 05 onde é possível admirar o Rio entre as cidades, a vegetação da Área de Preservação Permanente, e as edificações da Orla do Porto revitalizado. 


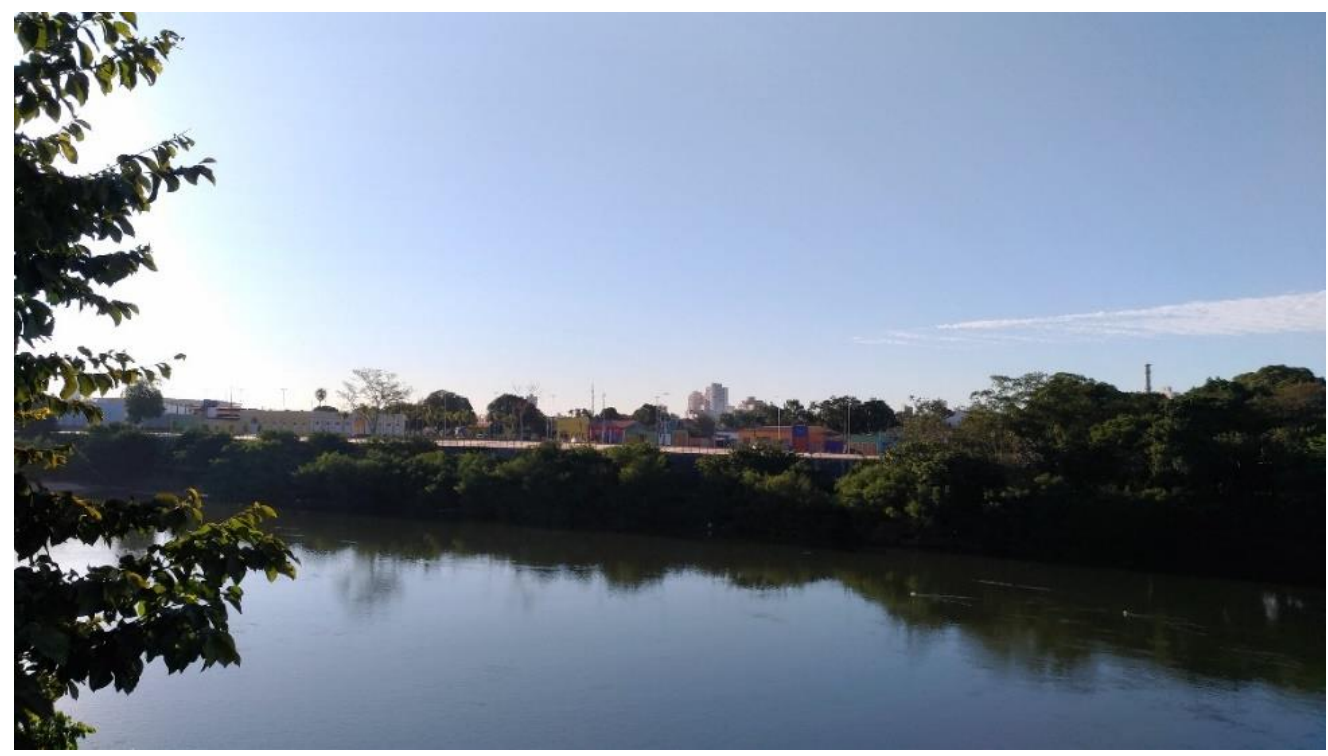

Figura 05 - Vista a partir da Ponte Júlio Müller

Fonte: Autora, 2017.

\section{Reflexões sobre o espaço em questão}

Tempo, fluxos e espaços unem a sociedade em rede como resume (CASTELLS, 1999), em a sociedade em rede, quando fala sobre o espaço dos fluxos. O tempo, os fluxos, e os espaços urbanos são unidos com as obras de arte da engenharia, quando existem cursos de água, as Pontes, que viabilizam os fluxos nas cidades. Mas com esse olhar pensamos que são apenas espaços transitórios, que ligam espaços separados por uma fronteira (o rio), e se olharmos com maior profundidade para essas obras, e nos perguntamos, o que realmente acontece nesses lugares? Temos ali novos mapas sociais com processos de reterritorialização, na ocupação dos espaços de Pontes e Viadutos, com usos apropriados ou não, habitação, arte, lazer, passeio, ou simplesmente o fluxo urbano, mas não apenas o fluxo de veículos como vemos ao olhar $a$ cidade de longe, e sim as pessoas, que passam por ali sim com muita frequência em veículos, em conjunto com pessoas que ocupam o espaço, e não apenas passam.

A ponte construída como possibilidade de conexões, como possibilidade de rompimento de fronteiras. Ela cria espaços, que em alguns casos, são vistos por distintas visões como espaços vazios, um entre espaços situado sobre a fronteira (sobre o rio), onde ocorrem processos de apropriações desse espaço com distintas identidades culturais na cidade contemporânea, o que mostra que a Ponte tem uma abrangência múltipla, que envolve diferentes agentes sociais. Pela falta de atenção do estado, pessoas recriam os usos desses espaços de forma marginalizada, irregular, estando à beira da cidade, construindo ocupações 
que oferecem riscos, como os moradores de rua, usuários de drogas, esportistas, artistas, que reterritorializam esses espaços antes vazios, entre os espaços e a fronteira.

A fronteira não é apenas uma linha mapeada cartograficamente e descrita em seus marcos geodésicos com a finalidade de separar duas ou mais unidades espaciais. Se assim o fosse, os problemas relativos aos limites territoriais se restringiriam à tecnologia empregada para proceder referido traçado e descrição. Quando se mencionam os termos "limite territorial" ou "fronteira", é necessário remeter-se às noções mais amplas de "território" e de "territorialidade". (SILVA; TOURINHO, 2017, p. 97)

Territorialidade essa que mostra as Pontes como elementos criados para cruzar fronteiras, para propor conexões entre os espaços delimitados pela fronteira, como um novo espaço, espaço que pode ser visto como "terras de fronteiras são, antes de tudo estratégicas que redefinem as relações entre Estados, nacionalidades, etnias e identidades". (FAULHABER, 2001, p. 105)

\section{Processos de reterritorializações no espaço criado com a construção da ponte}

No urbanismo, Gordon Cullen (2013) afirma que "Abrigo, sombra, conveniência e um ambiente aprazível são as causas mais frequentes da apropriação de espaço, as condições que levam à ocupação de determinados locais.” (CULLEN, 2013, p. 25), podemos observar então que esse abrigo, essa sombra, e em alguns casos esse ambiente aprazível pode ser encontrado no espaço criado na construção de Pontes e de Viadutos, e é o que ocorre abaixo da laje do tabuleiro da Ponte Júlio Müller, onde vamos perceber que "Do pavimento vulgar e banal do mundo agitado em que vivemos vislumbramos muitas vezes, num relance, o desconhecido, o caráter misterioso de uma cidade em que tudo é possível; o sublime e o sórdido, os rasgos de génio e a loucura" (CULLEN, 2013, p. 53) entendo assim como loucura, o modo de vida nas reterritorializações abaixo da ponte.

A forma de nossas obras de arte permite esse fluxo, mas permitem também outros Mapas no rizoma da cidade (DELEUZE; GUATTARI, 1995). Paralelo a cidade nos rios, por onde estão as pontes, temos a obviedade da pescaria que se mescla as atividades urbanas, e tem o espaço em baixo da ponte Júlio Muller como apoio das canoas cuiabanas que se vê ao caminhar pela pequena calçada na ponte, na Figura 6. A manutenção de aspectos históricos da cidade na cultura da pesca, em relação a transformação urbana é um aspecto estético importante na poética da cidade contemporânea (figura 7), visto nas edificações construídas abaixo da ponte, na comunidade de pescadores, o que contribui na construção de sua memória e valores culturais presentes na contemporaneidade. 


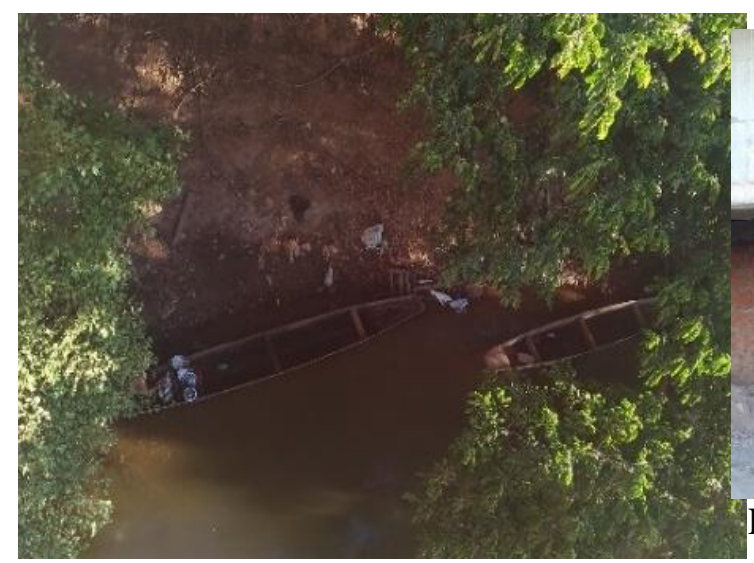

Figura 6 - Pescador na Ponte Júlio Muller. Fonte: Autora, 2017.
Figura 7 - Habitação em baixo da Ponte Júlio Muller.

Fonte: Autora, 2017.

Silva, M. L., \& Tourinho, H. L. Z. ao falar de território afirma que "Sua abrangência é múltipla, envolvendo diferentes espaços e agentes sociais, indo desde a ação do Estado delimitando as fronteiras de um país, por exemplo, até a definição de abrangência espacial das organizações comunitárias de bairros, de conjuntos habitacionais, de ocupações etc.” O que é claro no espaço abaixo da laje da ponte, com a criação de um "condomínio" de pescadores, com delimitações de espaço das casas construídas e espaços ocupados para o trabalho e lazer e inclusive com demarcações expressadas em frases, como pode ser visto na figura 08 que mostra a inscrição do alerta, de que este local está sendo filmado. (Silva, M. L., \& Tourinho, H. L. Z p. 97). Além da expressão na viga, que apresenta a identificação da comunidade, existe outra placa ainda no acesso ao local também com a identificação e com aviso que afirma estar proibido o uso de drogas no local.
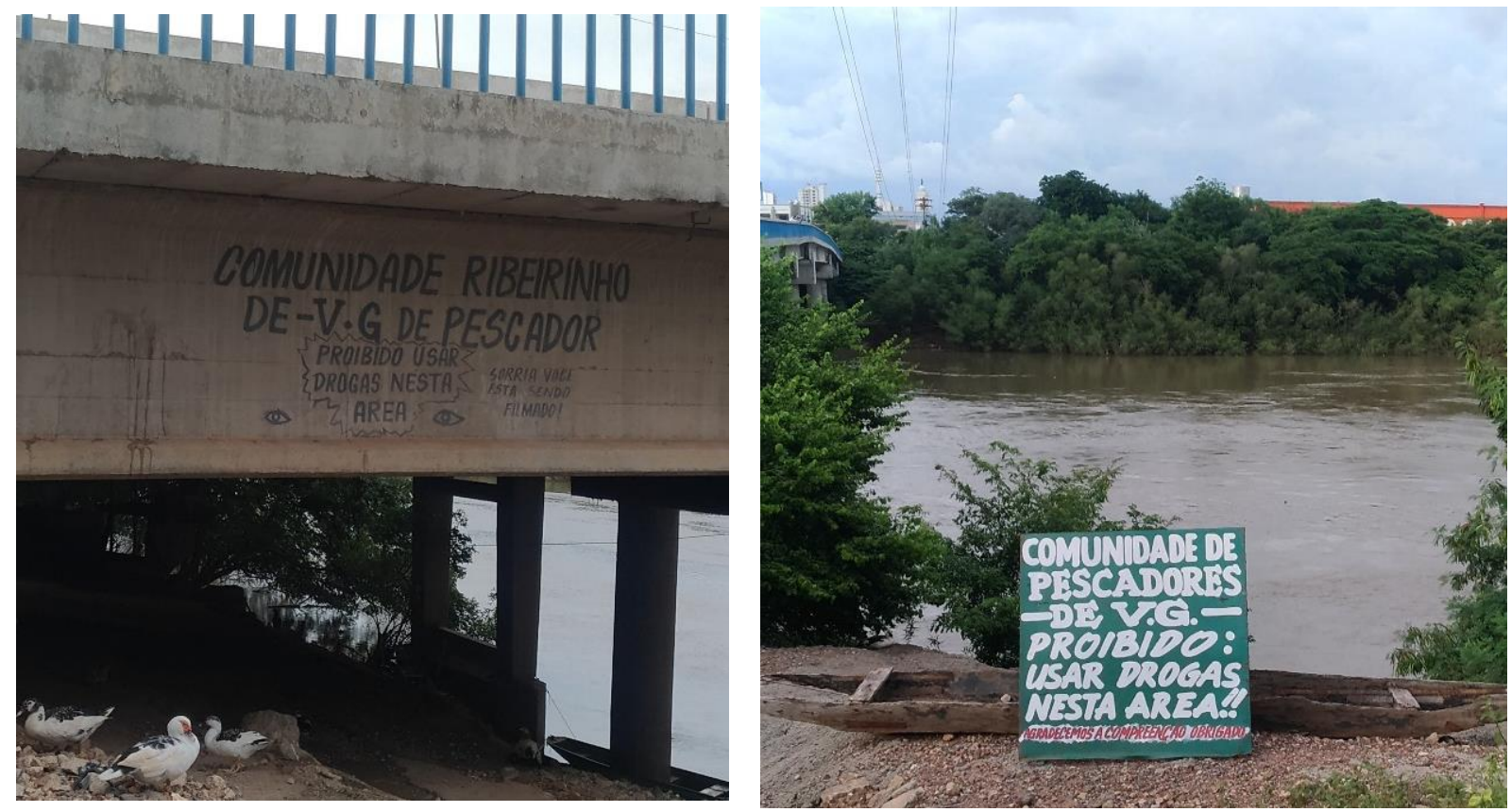
Figura 8 - Registro da comunidade e aviso sobre segurança.

Fonte: Autora, 2018.
Figura 8 - Registro da comunidade e aviso sobre drogas.

Fonte: Autora, 2018.

A limitação dada pelo rio Cuiabá também define a fronteira entre as cidades de Cuiabá e Várzea Grande, mas esse trabalho trás uma análise que vai além, então vale pensar a partir da definição e Hildebert Isnard, trazendo a ideia de que "As fronteiras são a cristalização dos limites da organização do espaço realizado por distintos projetos políticos, inclusive projetos não estatais" (Silva, M. L., \& Tourinho, H. L. Z, 2017, p. 98) tendo um sentido que pode ser mais fácil entendido com a definição de Claude Raffestin "A fronteira é zona camuflada em linha. As divisões político-administrativas são encaradas também como fronteiras (fronteiras internas), porque elas seriam a armadura de sustentação e de vitalidade da fronteira externa. Zonas e linhas fariam parte de um sistema de limites. (Silva, M. L., \& Tourinho, H. L. Z, 2017, p. 98)

Ao falar sobre pontes e viadutos, tratamos de espaços públicos, no entanto, ao olhar para as construções urbanas, vemos nas diferentes ocupações, retratadas na figura 2, na construção de modos de habitar alternativos o questionamento em relação entre o que são espaços públicos e privados ou ainda quais são os espaços marginais na criação do cotidiano (DE CERTEAU, 1998).

Os estudos teóricos referentes à cultura contemporânea, antropologia urbana, estéticas emergentes da cidade, globalização e cotidiano, entre outros temas que colaboram na construção do espaço urbano direcionam a necessidade de estudos em relação às distintas práticas de espaço que se dão nos espaços urbanos que são criados por Obras de Pontes e Viadutos, que permitem ressignificações e reterritorializações de espaços criados para o fluxo de carros ou de pedestres, com o uso e a ocupação do espaço para manifestações culturais e políticas por meio do grafite e pichação, o uso do espaço público como espaço privado para moradias (ilegais, nos padrões de urbanismo), manifestações culturais, de lazer (como o passeio pela ponte (quando isso é possível, pela sua concepção arquitetônica), considerando que em sua maioria são elementos de notoriedade turística e simbólica na cidade, em muitos casos o uso desses espaços para práticas esportivas, desde uma caminhada até o uso para skateparks/patinsparks ${ }^{3}$ entre outras opções, ou ainda distintas formas de construção na cidade contemporânea, afim de vermos além do sistema viário, mas como essas obras de arte se

\footnotetext{
${ }^{3}$ Espaços para prática de esportes como skate e/ou patinação.
} 
inserem na construção da cidade, porém em processos de criação de espaços de novas práticas urbanas.

\section{Considerações Finais: Pontes culturais possíveis}

A partir das reflexões nos estudos de cultura contemporânea, dos processos de concepção de pontes e viadutos e de uma linha histórica urbana, entre o objeto de análise em Cuiabá, na construção da cidade a partir do cotidiano citadino, observa-se que as obras de arte da engenharia construídas geralmente para ligar ou viabilizar fluxos, são monumentos na cidade, pontos de referência, estética, turística e cultural, mas muito além disso, são monumentos que compõem a tessitura da cidade contemporânea, porem em muitos casos, criam espaços onde podem ser percebidos problemas sociais, estéticos urbanos, que podem ser evitados ou repensados com a atuação conjunto multidisciplinar nesses projetos, tendo a necessidade conjunta do pensamento sociológico enquanto espaço cultural, na poética da cidade, afim de propor a população espaços onde a cidade contemporânea possa ser vivida (ao invés da criação de um novo espaço de fronteira social) mesmo que seja apenas durante os poucos segundos em que passamos por uma ponte ou ainda com a o bom aproveitamento dos vazios urbanos que são gerados na implantação de obra de arte na cidade, pois ali estão distintas relações que compõem um espaço multiterritorial, espaço que "corresponde a uma cartografia imaginaria dos citadinos que vivem em certas partes da cidade continuando a ter, sobre outros espaços, pelo menos algumas experiencias, ideias ou imagens" (AGIER, 2011, p. $67)$.

A partir dos fatos observados e narrados, é possível trazer à tona o questionamento sobre "O que mantem os indivíduos unidos? Que mecanismos sociais os integram ou desintegram?" (Durkeim in PAIS, 2006, p. 20), vendo nas pontes, "pontes" a fim de trazer sentidos para a vida nessa cidade contemporânea multifacetada. Por meio do olhar à um lugar diferente do comum é possível ver diferentes realidades de um "espaço público da cidade é um mosaico de "alegorias" que tem o condão de dar outros significados às manifestações esparsas da vida urbana." (PAIS, p. 23) e "Embora seja possível dizer que o homem tem uma natureza, é mais significativo dizer que o homem constrói sua própria natureza, ou, mais simplesmente, que o homem se produz a si mesmo.” (BERGER E LUCKMAN, 1985, p. 72).

A natureza citadina existente nos arredores do concreto da Ponte mostram um processo de ocupação desse local, onde os pescadores, ao realizar ali a estrutura de uma 
comunidade para o seu convívio faz o uso máximo do espaço, utilizando os diferentes níveis entre a cota da via pavimentada acima da ponte e a cota do nível de água do rio, vendo na prática que "Os desníveis, por sua vez, podem ser utilizados de maneira funcional, para unir ou separar a atividade dos diversos utentes duma via pública.” (CULLEN, 2013, p. 40).

De um modo geral, abaixo do nível médio do terreno, temos sensações de intimidade, inferioridade, encerramento ou claustrofobia enquanto acima desse nível podemos ser tomados de grande euforia, ou por sensações de domínio ou superioridade ou, ainda, sentirmo-nos expostos ou com vertigens. $\mathrm{O}$ ato de descer significa baixar ao encontro daquilo que conhecemos enquanto que o de subir implica ascender ao desconhecido. (CULLEN, 2013, p. 40)

Os pescadores criam ali um modo de vida urbano, ou paralelo a cidade, mesmo estando nela, eles têm nesse espaço uma mistura de relações de trabalho e sócio, históricas e culturais. "O certo é que, no decorrer da sua existência, o ser humano mantém e reproduz a sua relação com a natureza. Ele constrói, registra e retrata a construção desta natureza" (BERTOLOTO, 2006, p. 79) o que é possível refletir nos espaços urbanos presentes nas cidades com a construção de pontes e viadutos, tanto na sua inserção na paisagem urbana, enquanto espaço de fluxo de veículos como na vida, na cultura contemporânea urbana.

Cullen (2013, p. 30) fala da separação arquitetônica entre "dentro" e "fora" na união dos espaços, refletindo que o espaço externo em geral apresenta itens estáticos, no entanto afirma também que "Ao homem, não bastam as galerias de pintura; ele necessita de emoção, do dramatismo que é possível fazer surgir do solo e do céu, das árvores, dos edifícios, dos desníveis e de tudo o que o rodeia, através da arte do relacionamento." (CULLEN, 2013, p. 30) o que é percebido nas ocupações da ponte Júlio Muller, na relação com a pesca, com o rio, e até mesmo com os riscos que o espaço oferece, mas das possibilidades de estar junto na pesca, nas atividades dos finais de semana, o que fez com os pescadores criassem ali um espaço físico construído em conjunto com a estrutura da ponte, para o seu trabalho e para o seu lazer.

Em paralelo aos conceitos de fronteiras vistos, no urbanismo Cullen (2013, p. 66) traz esse olhar identificando como Cidade Secreta analisando uma foto de Birmingham que existem dois espaços diferentes que coexistem separados por uma ponte, o autor traz que "lado a lado, dois mundos completamente diferentes: a rua movimentada e ruidosa que atravessa a zona do comércio e dos negócios e que, em determinada altura, segue até à ponte sobre o canal, cuja bacia é silenciosa e deserta como uma cidade secreta" (CULLEN, 2013, p. 66), no entanto em nossa cidade secreta, ou seja, no espaço abaixo do tabuleiro da ponte, 
temos uma série de modos de vida escondidos, à margem da cidade metrópole, enquanto no pavimento da laje do tabuleiro passa o fluxo intenso viário entre as duas cidades, e as pessoas que ali passam começam a se apropriar do espaço construído para o V.L.T. para o acesso terrestre ou ainda a simples contemplação do espaço e vista privilegiada.

\section{Referências}

AGIER, Michel. Antropologia da cidade: lugares, situações, movimentos. São Paulo: Terceiro Nome, 2011. pp. 47-100.

BERGER, Petter L.; LUCKMAN, Thomas. A construção social da realidade: Tratado de sociologia do conhecimento. 24. ed. Petrópolis: Vozes, 1985.

BERTOLOTO, José Serafim. ICONOGRAFIA DAS ÁGUAS: O RIO E SUAS IMAGENS. Cuiabá: Catedral, 2006.

CASTELLS, Manoel. “O espaço dos fluxos". In: A sociedade em rede. São Paulo: Paz e Terra, 1999. pp. 467-521.

CULLEN, Gordon. Paisagem urbana. 70. ed. Lisboa: Arquitectura e Urbanismo, 2013. 202 p.

DE CERTEAU, Michel. "Terceira parte: Práticas de Espaço". In: DE CERTEAU, M. A Invenção do Cotidiano. 1. artes de fazer. $3^{\mathrm{a}}$ ed. Petrópolis: Vozes,

DELEUZE, Gilles; GUATARRI, Félix. Mil platôs: Capitalismo e esquisofrenia. São Paulo: 34, 1980.

PAIS, José Machado. Sociologia da vida cotidiana. Lisboa: Imprensa de Ciências Sociais, 2002.

FAULHABER, Priscila. A Fronteira na Antropologia Social: As Diferentes Faces de um Problema. Revista Brasileira de Informação Bibliográfica em Ciências Sociais - Bib, São Paulo, n. 51, p.105-125, 2001. Semestral.

SILVA, Marlon Lima da; TOURINHO, Helena Lúcia Zagury. Território, territorialidade e fronteira: o problema dos limites municipais e seus desdobramentos em Belém/PA. Urbe Revista Brasileira de Gestão Urbana (brazilian Journal Of Urban Management), Curitiba, v. 1, n. 9, p.96-109, jan. 2017. Trimestral. Disponível em:

<http://www2.pucpr.br/reol/pb/index.php/urbe?dd1=16361\&dd99=view\&dd98=pb >. Acesso em: 20 jul. 2018.

GAZETA DIGITAL. Gazeta Digital (Org.). Ponte Júlio Müller tem nova intervenção. 2014. Disponível em: <http://www.gazetadigital.com.br/editorias/cidades/pontejulio-muller-tem-nova-intervencao/415381>. Acesso em: $22 \mathrm{dez} .2018$.

WILSON PIRES DE ANDRADE (Olha Direto). Há 74 anos inaugurava a primeira ponte ligando Cuiabá a Várzea Grande.2016. Disponível em: 
$<$ http://www.olhardireto.com.br/artigos/exibir.asp?id=7800\&artigo=ha-74-anos-inauguravaa-primeira-ponte-ligando-cuiaba-a-varzea-grande>. Acesso em: 21 dez. 2018.

WILSON PIRES DE ANDRADE. O Documento. Primeira ponte sobre o rio Cuiabá comemora 76 anos. 2018. Disponível em: <http://odocumento.com.br/fatos-ememoria/primeira-ponte-sobre-o-rio-cuiaba-comemora-76-anos,28338>. Acesso em: 20 dez. 2018.

WILSON PIRES DE ANDRADE. Vg Notícias. Primeira ponte sobre o Rio Cuiabá comemora 76 anos. 2018. Disponível em: <https://www.vgnoticias.com.br/artigos/primeiraponte-sobre-o-rio-cuiaba-comemora-76-anos/44617>. Acesso em: 21 dez. 2018. 